\author{
Ärztliche Erfahrung beschränkt sich nicht auf medizinisches Fachwissen. \\ Sie entsteht auch aus den mehr oder minder alltäglichen, heiter, \\ ärgerlich oder nachdenklich stimmenden Erlebnissen mit Patienten, \\ Kollegen und Mitarbeitern. Senden Sie uns Ihre Geschichte an: \\ cornelius.heyer@springer.com.
}

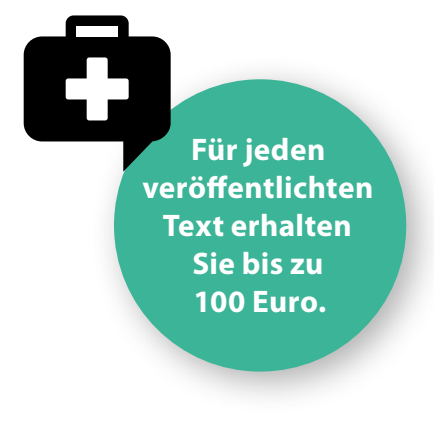

\title{
Schillernde Lebensgefahr aus dem Aquarium
}

_ Dieser junge Mann hätte auch in der Nacht hatte er sich nicht wohl gefühlt und heftigen Schüttelfrost gehabt. Nach einiger Zeit hatten die Beschwerden nachgelassen, inzwischen hatte er nur noch Kopfweh. Ob das mit der Krustenanemone zu tun haben könnte? Ich wollte schon den Kopf schütteln, als er von einem Bekannten berichtete, dem ÄhnGerichtsmedizin enden können. In der

liches widerfahren war. Krustenanemonen seien wohl sehr giftig.

Also „großes Konsil“: schnell gegoogelt, Wikipedia und ein paar weitere Seiten angesehen. Ja, Krustenanemonen verteidigen sich mit einem Gift, das über die Haut aufgenommen wird - und tödlich sein kann! Der Patient erzählte nun detailliert, wie er abends ein Meerwasseraquarium gesäubert hatte und dabei ver-

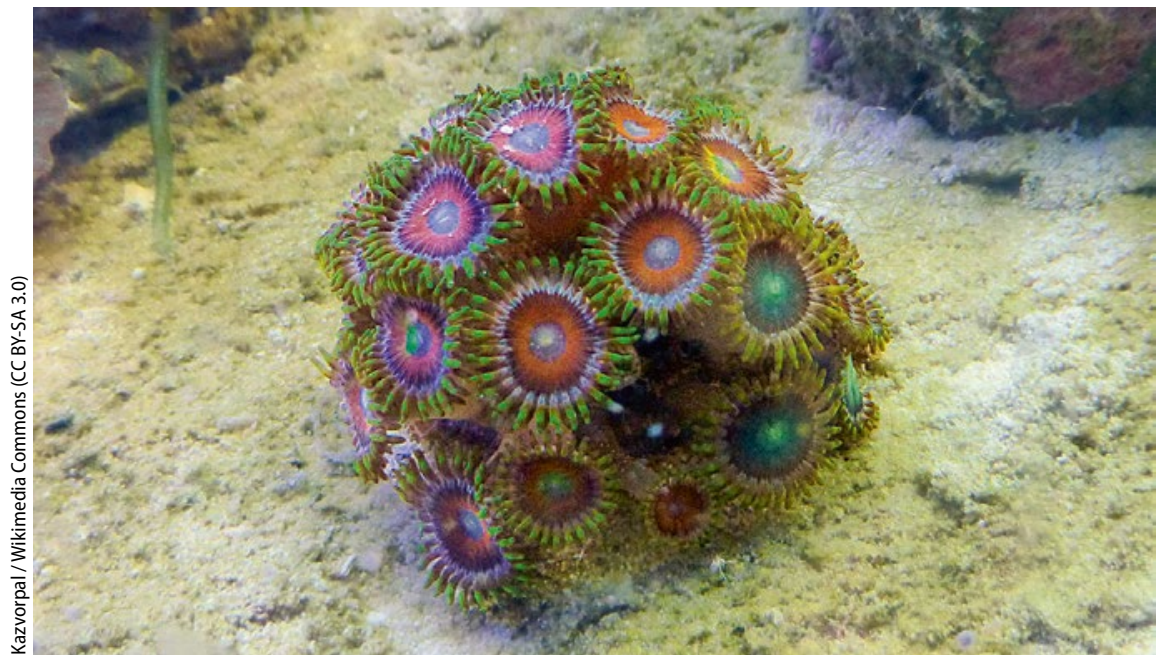

Krustenanemonen werden in der Aquaristik gern zur Farbgebung eingesetzt. sehentlich mit der bloßen Hand an eine Krustenanemone gekommen war. Er hatte Schleim gespürt. Nach sechs Stunden kamen die Beschwerden.

Sicherheitshalber rief ich den Münchner Giftnotruf an. Ich erfuhr, dass man Patienten ohne Bradykardie $150 \mathrm{mg}$ Prednisolonäquivalent gibt. Für meinen Patienten war es allerdings dafür zu spät, er war ja auf dem Weg der Besserung, auch wenn die Kopfschmerzen noch länger bestehen bleiben könnten.

Nicht auszudenken, wenn der allein lebende Patient nächtens gestorben wäre! Auf eine tödliche Vergiftung wäre doch niemals jemand gekommen. Die Sache ließ mir keine Ruhe, und weitere Recherchen verstärkten meine Sorge: Offenbar kann sich das Gift, Palytoxin, auch als Aerosol verteilen! Beim Reinigen des Aquariums ist also eine Atemschutzmaske angezeigt. Zum Glück hatte auch mein Patient schon recherchiert - und eine sehr biologische Lösung gefunden. Er hatte sich eine bestimmte Schneckenart bestellt, deren Leibspeise Krustenanemonen sind.

Michael Steinhauer, Gemünden

\section{Ein erfrischend deftiges Wort zur rechten Zeit}

Eigentlich war sie für diese lebensverändernde Diagnose noch viel zu jung, doch sie trug sie mit Fassung. Schon bald kam sie frisch operiert, rehabilitiert und ganz erstaunlich gut regeneriert in meine Spechstunde. Das Ergebnis war sensationell gut. Was sie quälte, war ihre
Narbe, die sich wie ein Reißverschluß über ihren Bauchnabel zog. Ihren neonfarbenen Bikini, mit dem sie alle im Schwimmbad ausstach, musste sie jetzt wohl an den Nagel hängen. Das gefiel ihr nicht. Auch eine Narbensalbe konnte sie nicht darüber hinwegtrösten.
In Anbetracht des guten Therapieverlaufs war das Lamento etwas inadäquat. Ich sah ihren Ehemann an und sagte nur ein Wort: „Scheidung.“ Die Antwort kam postwendend: „Mord.“ Wir verabschiedeten uns lachend.

Dr. Luise Hess, Darmstadt 